\title{
MODERNIDAD LITERARIA Y LA ENTRADA DE LAS MUJERES A LA ESFERA PÚBLICA EN LOS DISCURSOS DE BELLO, DE HOSTOS Y MISTRAL ${ }^{1}$
}

\author{
María Soledad Falabella Luco \\ Universidad Diego Portales \\ sfalabella@gmail.com
}

RESUMEN / ABSTRACT

La entrada a la esfera pública de mujeres se prefigura en la independencia cultural americana basada en la cultura letrada, encarnada en el prólogo de la Gramática de Andrés Bello. El proyecto de modernización cultural propuesto por Bello contiene dos impulsos: la voluntad pedagógica, que se revisará a través de un análisis de la propuesta de Eugenio María de Hostos, y el dialogismo lingüístico, que se configura como un espacio contiguo, polifónico, que busca dignificar al castellano de América frente al de España. Esta doble articulación de la cultura letrada prevé la incorporación de nuevas voces a la norma, lo que describiremos con el caso de Gabriela Mistral y su propuesta pedagógica.

PALABRAS ClAVE: género, modernidad, lingüística, América Latina, nación.

Women's entry into the public sphere can be prefigured in Latin American cultural independency strives, which were based on a lettered culture. The foreword to Andrés Bello 's Gramática, the embodiment of this culture, is a cultural modernization project that bears two impulses, one of pedagogical will and another of linguistic dialogism. The first impulse will be dealt with an analysis of Eugenio Maria de Hostos' discourse. The second one is built as a contiguous polyphonic space that seeks to dignify American Spanish in relation to the peninsular variation.

1 Este artículo forma parte del trabajo realizado en el proyecto FONDECYT n ${ }^{\circ} 1040663$ "Lengua materna, cuerpo y normatividad: de la América Hispana a la América Latina", donde me desempeñé como co-investigadora y María Cecilia Sánchez como investigadora responsable. 
This double articulation of the lettered culture allows for the incorporation of new voices into the norm, as is the case of Gabriela Mistral and her pedagogic discourse.

KEY WORDS: gender, modernity, linguistics, Latin America, nation.

\section{VOLUNTAD PEDAGÓGICA Y DIGNIDAD LINGÜÍSTICA EN LA GRAMÁTICA DE BELLO}

La Independencia de los países americanos significó una fragmentación de la unidad imperial articulada desde la metrópoli madrileña, rompiéndose la continuidad y unidad política, territorial y lingüística. Este trauma -herida en griego- sufrido por el cuerpo de la "Madre Patria", incluyó un corte lingüístico necesario para materializar la voluntad revolucionaria criolla (Sánchez, Félix 284). Su objetivo fue escindirse del imperio en pos de formar nuevas naciones independientes. Salvo Cuba y Puerto Rico, cuya "independencia" fue el motivo de la guerra del 98, este proceso se estabilizó paulatina y relativamente, consolidando nuevos proyectos nacionales hacia 1870 (Halperin-Donghi 242-287; Rama, La crítica 82). Se trató de un esfuerzo político concreto de hacer guerra, ganar batallas, dominar territorios y crear posibilidad política y dispositivos institucionales para el futuro gobierno y la unidad nacional.

A nivel político, la Independencia implicó el despliegue de dispositivos discursivos bélicos, lo que conllevó a la imposición de una lógica exclusivista en la que la ambigüedad era intolerable. Siguiendo una lógica unívoca-donde si no se era aliado, solo se podía ser enemigo- el primer objetivo de la Independencia fue la aniquilación del poder de España por sobre los territorios americanos. Sin embargo, el corte lingüístico y cultural con la "Madre Patria" no podía darse sobre la base de la lógica bélica de exclusión y aniquilación del enemigo, menos de un reemplazo absoluto de un cuerpo lingüístico, por otro. Un corte absoluto era irrealizable, la lengua como institución social era la base del orden que iba a permitir la futura gobernabilidad y el desarrollo político, social y cultural de las naciones republicanas americanas. Tal como lo enuncia el venezolano Andrés Bello (1781-1865), en el "Prólogo" a la Gramática de la lengua castellana destinada al uso de los americanos (1847): la independencia cultural se basaba en un cuerpo lingüístico ya existente y no una tabula rasa, un comenzar de nuevo ex nihilo (18).

En efecto, a diferencia de la estrategia política y territorial de las guerras independentistas, la estrategia de la emancipación lingüística y cultural no 
fue la de una lógica exclusivista. Con la Gramática, Bello junto con fundar una nueva normatividad lingüística, articuló las bases para una independencia cultural cuyo objetivo era lograr una instalación contigua de la lengua americana al lado del castellano de España. No se trataba de borrar la lengua del enemigo, sino reconfigurar sus límites y formas para que esa lengua se hiciera propia a las naciones independientes. Tal como lo señala Iván Jaksic en su libro Andrés Bello, la pasión por el orden: "La solución de Bello era no abandonar el lenguaje que había unido a España y sus colonias, sino más bien retenerlo y construir sobre su base una identidad hispanoamericana que incorporara las nuevas realidades políticas y lingüísticas" (269). De esta forma, la Gramática se configuró como el texto paradigmático para la formación de la identidad lingüística moderna en las nuevas naciones (Ramos 65-66, Gómez Asencio 16).

Para empezar, ya el título "Gramática de la lengua castellana" no solo subrayaba la apropiación estratégica del dialecto del latín que se hablaba en América, sino que también daba cuenta de una visión conscientemente reformista de estar fundando algo nuevo (Torres Quintero 1). En efecto, en el "Prólogo" el autor advirtió:

No tengo la pretensión de escribir para los castellanos. Mis lecciones se dirigen a mis hermanos, los habitantes de Hispano-América... Juzgo importante la conservación de la lengua de nuestros padres en su posible pureza, como un medio providencial de comunicación y un vínculo de fraternidad entre las varias naciones de origen español derramadas sobre los dos continentes (Bello 18).

Bello instaló de esta forma en el centro de su proyecto un nuevo sujeto, "los hermanos americanos", los que debían conservar el rasgo compartido del cuerpo de la lengua madre "de origen español" que los unía en fraternidad. El propósito era darle un cauce común al "adelantamiento prodigioso de todas las ciencias y las artes, la difusión de la cultura intelectual y las revoluciones políticas" (Bello 18). La lengua tenía para Bello un valor claro y preciso: el de expresar las nuevas ideas para lo cual se necesitaban "cada día nuevos signos" que debían normarse según el buen decir. En efecto, esta característica del discurso Bello lo enriqueció, acercándola a "muchos de los objetivos de los intelectuales anteriores a Martí", según señala Julio Ramos en Desencuentros de la modernidad en América Latina (56). La Gramática buscó proveer un marco normativo para encausar las ideas necesarias para consolidar las nuevas naciones, la "república de las letras", al decir de Ramos, un espacio 
donde ciencias y literatura conviven y en el cual la elocuencia tiene el rol de la autoridad común (62).

Es más, la Gramática se articuló expresamente como una gramática flexible y adaptable a cada nación, un dispositivo cuyo objetivo era integrar a "sus hermanos" a la nueva normatividad local por medio de la pedagogía: “... para proporcionar a los profesores del primer curso el auxilio de las explicaciones destinadas al segundo, si alguna vez las necesitaren" (Bello 17). Bello destacó el rol especializado de "los profesores", cuya tarea era enseñar la lengua de forma racional y con especial atención a los usos locales. Asimismo, reconocía la necesidad de tener en cuenta la heterogeneidad de "los hermanos americanos", integrando el problema de la implementación práctica del proyecto de la Gramática a su estructura: "Hay en la gramática muchos puntos que no son accesibles a la inteligencia de la primera edad; y por eso he juzgado conveniente dividirla en dos cursos". La estructura de la obra tuvo en cuenta a dos nuevos sujetos, los profesores por un lado, y por otro, una subjetividad más flexible y heterogénea que incluye a personas cuya inteligencia es de "la primera edad", no iniciados en el sistema:

Creo, además, que esas explicaciones no serán enteramente inútiles a los principiantes, porque, a medida que adelanten, se les irán desvaneciendo gradualmente las dificultades que para entenderlas se les ofrezcan. Por este medio queda también al arbitrio de los profesores el añadir a las lecciones de la enseñanza primaria todo aquello que de las del curso posterior les pareciere a propósito, según la capacidad y aprovechamiento de los alumnos (Bello 17).

Los profesores, como sujetos, adquirieron un rol articulador. A su vez, a sus "hermanos americanos" les atribuye un espacio abierto para la autosuperación a través de la educación. Con ello, Bello sentó las bases para un futuro de "integración cultural", dando cabida a un modelo abierto a la innovación y la creación en función de la eliminación de "estorbos a la difusión de las luces, a la ejecución de las leyes, a la administración del Estado, a la unidad nacional" (Bello 19). De esta forma, la Gramática entrega las reglas y métodos para la configuración y el crecimiento regulado de los cuerpos lingüísticos nacionales y los sujetos que lo hablaban. En efecto, Ramos plantea que:

Para Bello las letras, paradigma de la elocuencia, eran un modo de ajustar la lengua a las necesidades del proyecto modernizador. Las letras proveían el saber preliminar requerido para formar discursos 
efectivos y útiles. Más aún, las letras eran un instrumento de la formación de sujetos disciplinados; sujetos de la ley, subordinados al orden general y capaces incluso de administrarlo (65).

El sujeto disciplinado por la ley que articuló Bello es distinto al letrado colonial enunciado por Ángel Rama en su libro fundamental para el pensamiento latinoamericano, La ciudad letrada. No se trataba de un decodificador de las leyes que vienen de la metrópoli imperial, sino un nuevo sujeto, el profesor, cuya labor no era solo la educación de las masas en el buen uso de la norma gramatical nacional, sino que incluyó un espacio abierto a la heterogeneidad para adaptar la Gramática a la realidad local, administrándola. Se creó con ello las bases estructurales para la esfera pública moderna.

Cecilia Sánchez, en Escenas del cuerpo escindido propone leer el cuerpo lingüístico americano posindependentista como un cuerpo ya fisurado, fragmentado tanto por el contacto con lenguas bárbaras locales, como migrantes. Ante este cuerpo herido, la respuesta de Bello es de reparar las fisuras, y su herramienta fundamental es la Gramática, la que debe curar la herida de la babelización del español en América (Sánchez, Escenas 241-245). El gesto reparador en la Gramática fue complejo, contempló la integración de nuevos sujetos diferentes entre sí. Además de las revitalizaciones de la lengua que quedaban al criterio del profesor, en su "Prólogo" a la Gramática se proyecta una voluntad doble: un dispositivo que debió imponer orden y racionalidad, y por otro lado, un dispositivo dialógico entre distintas voces (la local y la universal), espacio que en potencia es polifónico y heterogéneo, a la vez 2 . A nivel estructural, se pasa a regular las formas de orden e integración de la multiplicidad de voces en la emergente esfera pública, espacio tensionado y paradójico, en el cual tendrán lugar las luchas y desencuentros entre los nuevos sujetos. Así, la Gramática permitió la apertura hacia la realidad local y la integración de nuevas voces, llevando a cabo "una modernización posible

2 Con este gesto de contigüidad, Bello abre un espacio en el que en potencia pueden surgir una multiplicidad polifónica de voces autónomas: para empezar, entre el castellano de América y el castellano de España. Abre lo que Mikhail Bakhtin llamará un espacio dialógico. (Bakhtin 1994).

Antonio Cornejo Polar, crítico peruano, concibe el encuentro entre el español de España y las lenguas autóctonas como un conflicto traumático que generará la heterogeneidad lingüística. Sin embargo, Cornejo-Polar enmarca de manera muy precisa su conceptualización a una lucha lingüística entre la oralidad de los pueblos originarios y la escritura de la metrópoli. En el 
y deseada", al decir de Ramos, y el mapa de ruta para lograrla ${ }^{3}$. Este gesto, junto con constituir la Gramática americana en una normatividad capaz de dialogar con las otras del mundo, incluyendo la de España, se constituye en un dispositivo ideológico para la formación de sujetos letrados y la reproducción de los mismos dentro de una institucionalidad pedagógica, moderna, racional, abierta a los principiantes. Con un gesto análogo al de la gramática de Nebrija en 1492, quien en su prólogo famosamente declara que "siempre la lengua fue compañera del imperio", en la Gramática de Andrés Bello se reproduce un sistema de ordenamiento letrado que en relación con el antiguo imperio, como referente de autoridad, no busca su aniquilación, sino lograr autonomía, reconocimiento y dignidad.

La necesidad de vincularse contiguamente con el acervo cultural lingüístico del enemigo, potenció un proceso de reconocimiento mutuo:

Si de raíces castellanas hemos formado vocablos nuevos, según los procederes ordinarios de derivación que el castellano reconoce, y de que se ha servido y se sirve continuamente para aumentar su caudal, ¿qué motivos hay para que nos avergoncemos de usarlos? Chile y Venezuela tienen tanto derecho como Aragón y Andalucía para que se toleren sus accidentales divergencias (Bello 19).

Apelando a la vergüenza y los derechos, el autor le infunde a su discurso una filosofía liberal que clama por la constitución de sujetos emancipados con derechos y dignos de honra lingüística, acto necesario para la constitución de naciones libres y autónomas frente al antiguo yugo colonial. Para ello, deja a criterio de los profesores la integración de nuevas voces. La ideología liberal

caso de Bello y para trazar su genealogía, usar la heterogeneidad lingüística planteada por Cornejo Polar sería un abuso de su sentido.

Sin embargo, el mismo Antonio Cornejo Polar plantea la cercanía de su concepción heterogénea de las literaturas andinas como una concepción emparentada con la de "dialogismo" de Bakhtin. En Escribir en el Aire señala que la teoría de la heterogeneidad ...

... en su nueva forma, asociada con la plurivocidad, esta concepción del objeto conlleva una epistemología y una ética, en torno a las cuales termina de anudarse el "principio dialógico" bajtiniano (Cornejo Polar 37).

3 Siguiendo a Julio Ramos:

Bello escribe sobre el deseo posible. En todo caso, es notable la voluntad racionalizadora, aún en esos discursos que postulaban la carencia de la racionalización. De ahí que podemos leer el lugar tan particular de Bello, no tanto como un desvío de la readlidad, sino como paradigma de una modernización posible y deseada (58). 
y romántica de la independencia cultural americana se sustentó no solo en normatividad restrictiva, sino también validando los usos y prácticas que se dan en la cohesión imaginaria del castellano de América, siempre mediadas por el letrado de élite que practica "el arte de hablar correctamente" (Bello 20). Así también lo señala Bernardo Subercaseax: "Su intransigencia liberal lo predispone a un liberalismo que hace hincapié en el desarrollo del individuo y en el carácter absoluto de la libertad, más bien que en el aspecto económico o en la democratización efectiva de la sociedad" (42).

Esa doble articulación entre orden y dignidad lingüística previó la incorporación futura de nuevas voces americanas a la norma: "Si según la práctica general de los americanos es más analógica la conjugación de algún verbo, ¿por qué razón hemos de preferir la que caprichosamente haya prevalecido en Castilla?" (Bello 19). La norma debía reflejar la "práctica general" americana, gesto que posiciona estratégicamente al castellano de América contiguo al castellano de España, generando un espacio polifónico con potencia democratizadora, gesto clave para la legitimación del espacio letrado tensionado y múltiple en su heterogeneidad ${ }^{4}$. Al articular la pedagogía y su oficio con la "práctica general" en potencia, sentó las bases normativas para abrir las puertas de la norma letrada a nuevos sujetos provenientes de

$4 \quad$ Aunque en Bello el castellano que se valora y constituye en norma es la lengua hablada por los letrados, hay un gesto ético cuyo potencial es democratizante (potencial fundamentalmente unido al espacio dialógico, según Bakhtin). El valor ético de este gesto permite que desde España exista un discurso que valore lo americano. Un ejemplo es Amado Alonso quien proclama más de un siglo después de su publicación que "La Gramática de la lengua castellana de Andrés Bello, escrita hace más de un siglo, sigue hoy mismo siendo la mejor gramática que tenemos de la lengua española".

Por otro lado, la crítica literaria y cultural hispanoamericana refleja una inferioridad sintomática, y cuyas huellas aún se evidencian cuando Rama señala: "Se diría que los escritores del continente sienten que trabajan con un instrumento prestado y al que muchas veces encaran como ajeno. Y algo de eso hay" (Rama, Crítica literaria 29).

De hecho Rama se acoge al proyecto unificador de la lengua española en América:

La comunidad de la lengua es la que autoriza una literatura hispanoamericana, aunque es ésta una concepción todavía provisoria, previa a otra definitiva. La literatura general de lengua española, desde sus orígenes medievales hasta su expansión actual, en distintas regiones del mundo (Rama, Crítica literaria 30).

Rama subraya así el éxito del proyecto de Bello, utópicamente a la reparación de la fisura original, y proyecta hacia un futuro reconocimiento de un cuerpo unificado de producción lingüística aún más amplia, cuya diversidad geopolítica se legitima y autoriza éticamente en el acervo de la práctica cotidiana del español. 
los grupos excluidos de la esfera pública: esclavos, pueblos originarios y la "otra" mitad de la población, las mujeres, cuya incorporación es un hito vital para la modernización.

En efecto, el diseño estructural de la Gramática estaba dirigido a integrar a no iniciados a las nuevas comunidades lingüísticas nacionales. Sin embargo, históricamente la esfera pública se había constituido en base a la exclusión de más de la mitad de la población: el gran número de los marginados incluyó mujeres, hombres analfabetos sin propiedad y niños (Landes 158), lo que contradecía este dispositivo integrador. En consecuencia, la nueva normatividad de la Gramática abierta a la heterogeneidad local por medio de la integración de los no iniciados produjo contradicciones y tensiones en la autorización de aquellos nuevos sujetos que buscaban legitimación en la esfera pública, como por ejemplo, Gabriela Mistral.

\section{LA NORMALIZACIÓN UTÓPICA DE LAS MUJERES: EUGENIO MARÍA DE HOSTOS Y LA MORAL DE LA RAZÓN PEDAGÓGICA}

Eugenio María de Hostos (1839-1903), puertorriqueño, letrado en asuntos jurídicos, pedagógicos y filosóficos, fue un eterno migrante por territorios de América. Vivió en Chile entre 1871-1896 donde participó activamente de la escena educativa y la sociedad en general. Sus publicaciones incluyen "Conferencias Sobre la educación Científica de la mujer" (1872), "Reforma de la enseñanza en Chile" (1888), "Reforma del plan de estudios de la Facultad de Leyes en Santiago" (1888). Fundó la "Escuela Normal" y su carrera en Chile culmina con la dirección del Liceo Miguel Luis Amunátegui entre el 1889 y el 1898.

5 La historiadora Joan Landes demuestra de qué manera el pacto liberal republicano es un pacto efectuado por los hombres, adultos, blancos y propietarios. En efecto, detrás del lema de la fraternidad republicana se esconde la exclusión de las mujeres, y de otros grupos tradicionalmente marginados, de aquellos derechos otorgados a los ciudadanos burgueses universales:

The universal bourgeois subject was from the outset a gendered subject. Only male rights to full individuality were protected. The revolt against the father was also a revolt against women as free and equal public and private beings. Undeniably, then, liberty and equality came to be overshadowed by fraternity (the brotherhood of men) within the new order (158).

Esta situación perdura hasta el presente en muchos aspectos. Así, empezando por casa, aún hoy las mujeres casadas en Chile no tenemos los mismos derechos que los hombres. 
El discurso de de Hostos profundizó el proyecto de modernización enunciado en el prólogo a la Gramática de Bello. Al igual que su antecesor, de Hostos hizo uso de recursos retóricos bélicos con lógica exclusivista para organizar su discurso modernizador; a diferencia de Bello, cuyo proyecto discursivo se abrió hacia la heterogeneidad, redujo su lógica a un objetivo trascendental y unívoco. De Hostos trascendió la disyuntiva entre el saber y el buen decir, colapsando la diferencia entre el saber y el poder que organizaba el discurso de Bello e instaló una nueva dicotomía entre el saber/poder y la justicia. Como veremos, la impronta moral de justicia de de Hostos se materializó en la demanda por la educación científica de las mujeres como derecho.

Un propósito fundamental impulsado por el discurso de este intelectual era permitir que la "República convaleciera" de los traumas que impedían la modernización. En su discurso "El propósito de la Normal" (1882) señalaba:

Era indispensable formar un ejército de maestros que, en toda la República, militara contra la ignorancia, contra la superstición, contra el cretinismo, contra la barbarie. Era indispensable, para que esos soldados de la verdad pudieran prevalecer en sus combates, que llevaran en sus mentes una noción tan clara, y en la voluntad una resolución tan firme, que, cuanto más combatieran, tanto más los iluminara la noción, tanto más estoica resolución los impulsara (Obras 287).

Los nuevos letrados, los hermanos americanos de los que hablaba Bello, debían "formar un ejército de maestros", que debía lograr "la emancipación mental". Los profesores eran para de Hostos "soldados de la verdad", cuyos "combates" son impulsados por una resolución "estoica" propia de un clima militar. El objetivo era sanar los traumas de la ignorancia, superstición, cretinismo, barbarie a través de un método "razonado" y "armonizador", sanador.

La doble articulación que vimos en Bello entre orden racional y dialogismo, se vio reducida en el discurso de de Hostos a una voluntad única, cuya lógica fue la de ordenar, unificar y sanar las diferencias según un criterio ético y teleológico: la justicia. Con ello, el intelectual puertorriqueño estableció las bases para la institución de los profesores, constituyendo al magisterio como una nueva forma de ser, una nueva subjetividad militar y republicana. Siguiendo a Ramos, a diferencia de Bello, la lógica del discurso que legitima a los nuevos maestros militantes de la verdad y la justicia se fundó sobre una lógica excluyente de la ambigüedad, que buscaba superar la brecha entre el saber y el decir que tanto preocupaba a Bello: 
En Bello no hay disyunción entre pensar y expresar: el saber decir, el dominio sobre la expresión, es la condición de la actividad raciocinante, sobredeterminando incluso la distinción entre una "buena" o "mala" idea, así como entre un "buen" o "mal" ciudadano.

En cambio Hostos propone "una enseñanza verdadera: la que se desentiende de los propósitos históricos, de los métodos parciales, de los procedimientos artificiales, $\mathrm{y}$ atendiendo exclusivamente al sujeto del conocimiento, que es la razón humana, y al objeto de conocimiento, que es la naturaleza, favorece la cópula de entrambas" (82).

Así, para de Hostos la enseñanza "verdadera [es] la que se desentiende de los propósitos históricos, de los métodos parciales, de los procedimientos artificiales". En torno a ello, señaló en su tratado Ciencia de la pedagogía: "Saber y poder se han ido haciendo sinónimos desde que la democracia ha fundado la igualdad jurídica, y desde que la igualdad jurídica ha descubierto su punto de apoyo en el aumento individual y colectivo de la cultura" (Obras completas. Forjando 164). En su discurso buscó enfatizar una emancipación a través de la igualdad, subrayando la superación de las diferencias del acceso al poder e instalando al centro de la educación la justicia "científicamente verdadera" como objetivo trascendental.

En efecto, el discurso de Eugenio María de Hostos sentó así las bases éticas para la conformación de una nueva ciudadanía de moral pedagógica, que tenía a la justicia como telos. La demanda fundamental fue la igualdad y justicia entre los sexos -cuestión que ya treinta años antes había sido planteada por Francisco de Bilbao en "Sociabilidad Chilena" (1843). Ávido lector del liberal John Stuart Mill (Rojas 455), de Hostos hace de la libertad el fundamento de su pensamiento y aboga incesantemente por la independencia de Puerto Rico y Cuba, aún bajo dominio español. Al igual que Mill lucha por la libertad de los subyugados: las mujeres, los esclavos y las colonias. De esta forma, profundiza la impronta por la emancipación y la dignidad instalada en la cultura letrada moderna.

En 1873 fue invitado a la Universidad de Harvard, EE.UU., donde leyó La educación científica de la mujer, discurso clave que impulsó la causa del acceso de las mujeres a la educación, especialmente en Chile. Sostiene que las leyes de los hombres son una infracción a la "Ley eterna de la naturaleza [qué] es la igualdad moral del hombre y de la mujer" (La educación 44), haciéndose cargo de la injusticia e irracionalidad histórica de la configuración legal, social y cultural que subordinaba las mujeres a la voluntad de los hombres (La educación 44). Las mujeres debían ser parte de los procesos de 
emancipación, por ello se debía modernizar el sistema educativo chileno e integrar las mujeres a la educación. Si no se lograba igualdad entre hombres y mujeres, no podía existir una liberación verdadera, ni una democracia en los hechos. De esta forma, en La educación científica de la mujer depositaba en ellas "el germen de la nueva vida social, del nuevo mundo moral que en vano reclamáis de los gobiernos, de las costumbres, de las leyes" (La educación 43), responsabilizando al género masculino "de los males que causan nuestra continua infracción de las leyes eternas de la naturaleza", esto es, "la igualdad moral del hombre y de la mujer":

Los que hacemos las leyes para nosotros, para el sexo masculino, para el sexo fuerte, a nuestro gusto, prescindiendo temerariamente de la mitad del género humano, nosotros somos responsables de los males que causan nuestra continua infracción de las leyes eternas de la naturaleza. Ley eterna de la naturaleza es igualdad moral del hombre y de la mujer, porque la mujer, como el hombre, es obrero de la vida (De Hostos, La educación 44).

Argumentó que la injusticia de excluir sistemáticamente de la educación científica a las mujeres las ha construido como seres de "corazón afectuoso", "cerebro ocioso" y "espíritu erial". La culpa la ha tenido la educación:

Educada exclusivamente como está por el corazón y para él, aislada sistemáticamente como vive en la esfera de la idealidad enfermiza, la mujer es una planta que vegeta, no una conciencia que conoce su existencia; es una mimosa sensitiva que lastima el contacto de los hechos, que las brutalidades de la realidad marchitan; no una entidad de razón y de conciencia que amparada por ellas en su vida, lucha para desarrollarlas, las desarrolla para vivirlas, las vive libremente, las realiza. (...) eso han hecho de la mujer los errores que pesan sobre ella, las tradiciones sociales, intelectuales y morales que la abruman (De Hostos, La educación 43).

La exclusión de las mujeres del acceso a la educación era un mal que había que denunciar y erradicar para promover "la esperanza de un nuevo orden social, la esperanza de la armonía moral e intelectual" (De Hostos, La educación 43). Con ello, la educación científica era la necesaria restauración para las mujeres de su derecho a ser responsable de su vida como humana: "Se debe educar a la mujer para que sea ser humano, para que cultive y desarrolle sus facultades, para que practique su razón, para que viva su conciencia, no para 
que funcione en la vida social con las funciones privativas de mujer" (De Hostos, La educación 46-47).

Así como Bello fundó las bases para el sujeto profesor articulador e integrador de la diversidad de los potenciales ciudadanos aún no iniciados en la normatividad, de Hostos autorizó a la mujer letrada educada científicamente como sujeto, cuyo ejercicio profesional tenía como objetivo devolverle "al arte de la palabra, escrita o hablada, el fin esencial a que corresponde". Junto con ello, debía dar cuenta de la "verdad filosófica", posibilitando al pensador "descubrir la rehabilitación de esferas enteras de pensamiento" (De Hostos, $L a$ educación 42). Las mujeres tenían un rol especial por cumplir: comunicar el sentimiento que despertara "el amor de la verdad en los pueblos no habituados en pensarla". Señala el autor:

Como el calor reanima los organismos más caducos, porque se hace sentir en los conductos más secretos de la vida, el sentimiento despierta el amor de la verdad en los pueblos no habituados a pensarla, porque hay una electricidad moral y el sentimiento es el mejor conductor de esa electricidad. El sentimiento es facultad inestable, transitoria e inconstante en nuestro sexo; es facultad estable, permanente, constante, en la mujer. Si nuestro fin es servir por medio del arte literario a la verdad, y en el estado actual de la vida chilena el medio más adecuado a ese fin es el sentimiento, y el sentimiento es más activo y por lo tanto más persuasivo y eficaz en la mujer, por una encadenación de ideas, por una rigurosa deducción llegaréis, como he llegado yo, a uno de los fines contenidos en la base primera: la educación científica de la mujer (De Hostos, La educación 42).

Vemos cómo de Hostos defendió y re-definió el espacio letrado en función de la razón científica, cuyo resultado debía ser la educación científica de las mujeres: su discurso usa la ciencia y su "rigurosa deducción" como dispositivo legitimador.

Es más, el fin último de la educación científica de las mujeres era la integración de "los pueblos no habituados a pensar [la verdad]" -léase grupos marginados- por medio del nuevo "arte literario" que era capaz de comunicar el amor a la vedad. Este discurso deposita la llave para trascender hacia el futuro utópico en el "arte literario":

Cuando se ha atribuido al arte literario el fin de expresar la verdad filosófica; cuando se le atribuye como regla de composición y de crítica el deber de conformar las obras científicas a los hechos 
demostrados positivamente por la ciencia, y el deber de amoldar las obras sociológicas o meramente literarias al desarrollo de la naturaleza humana, se ha devuelto al arte de la palabra, escrita o hablada, el fin esencial a que corresponde; y el pensador que en esa reivindicación del arte literario ha sabido descubrir la rehabilitación de esferas enteras de pensamiento, con sólo esa rehabilitación ha demostrado la profundidad de su indagación, la alteza de su designio (De Hostos, La educación 42).

El proyecto letrado recobró su lugar disputado en los procesos de modernización, al ser éste el dispositivo clave para lograr la emancipación mental y espiritual, y el progreso en América Latina (Ramos 66-67). De Hostos legitima la inclusión de las mujeres de forma racional, estableciendo una moral en pos de la verdad y la justicia que defiende el lugar ya socavado por los procesos de modernización de la cultura letrada. Promueve la emergencia de un nuevo sujeto, la mujer con educación científica autorizada para participar en la esfera pública. Veremos cómo Gabriela Mistral construye su legitimidad como autora en base a este dispositivo para autorizarse como la primera mujer que surge en la esfera pública letrada a nivel tanto local como global.

\section{AUTORIZACIÓN Y LEGITIMIDAD DEL SUJETO AUTODIDACTA EN EL DISCURSO DE GABRIELA MISTRAL}

Los proyectos discursivos de emancipación cultural de Andrés Bello y Eugenio María de Hostos funcionaron en base a dispositivos retóricos que, en el caso del primero, entregaban las reglas y métodos para la configuración y el crecimiento normado de los cuerpos lingüísticos nacionales, después del traumático corte con la "Madre Patria". La Gramática aspiraba a regular la incorporación de aquellos y aquellas que aún no formaban parte de la norma letrada y ciudadana. Además, como objeto libro era en su estructura un dispositivo que tenía la capacidad de educar integrando al sujeto autodidacta. Con ello, los profesores que enseñaban letras adquirieron un nuevo rol articulador de intérpretes e intermediarios y establecieron las estructuras para la potencial integración de los grupos iletrados: a nivel retórico los nuevos "hermanos americanos" podían habilitarse por medio de la auto-superación.

Eugenio María de Hostos impulsó un discurso que institucionalizó al profesorado: ejércitos de maestros normales, "soldados de la verdad," debían "prevalecer en sus combates" al tener un ideal claro y común, esto es, la libertad 
de la conciencia política y social emancipada, con lo cual se cumpliría con la sanación del cuerpo nacional traumado. Para su proyecto era fundamental el reconocimiento de igualdad de derechos y dignidad, lo que se lograba a través del acceso a la educación. El proyecto de de Hostos profundizó e implementó el discurso independentista del "Prólogo" a la Gramática de Bello, consolidando una institucionalidad pedagógica a lo largo de América Latina en general, y particularmente en Chile. De forma destacable legitimó la inclusión de las mujeres en la esfera pública en función de un discurso racional. Apelaba al restablecimiento de un orden perdido: devolver "al arte de la palabra, escrita o hablada, el fin esencial a que corresponde" (De Hostos, La educación 42).

Estas dos articulaciones discursivas, la de Bello y la de de Hostos, prefiguraron la emergencia de un sujeto como Gabriela Mistral: mujer mestiza que autorizó su discurso en función de una razón modernizadora, ejerciendo como maestra, poeta y ensayista. Su voz se legitimó a partir de su condición de mujer latinoamericana de trayectoria autodidacta y origen rural. Es más, estamos ante un sujeto paradigmático: su producción discursiva abarcó desde fines del siglo XIX hasta mediados del XX (1899-1957), momento clave de la institucionalización de la modernidad latinoamericana en general y Chile en específico. Mistral fue una de las primeras mujeres que se constituyó como sujeto letrado en la esfera pública, primero a nivel local y luego a nivel global para los pueblos de habla hispana. Nació en 1889 con el nombre de Lucila Godoy Alcayaga en Vicuña, un pequeño pueblo al norte de Chile, llegando a ser conocida como "la Maestra de América" y ganando en prestigioso Premio Nobel. Ejerció el magisterio sin contar con educación formal ni títulos académicos, camino que, como vimos, fue en parte legitimado por el discurso de la tradición letrada liberal. Aprendió el oficio trabajando con su hermana en una escuelita rural. En palabras de la autora:

Empecé a trabajar en una escuela de la aldea llamada Compañía Baja a los catorce años, como hija de gente pobre y con padre ausente y un poco desasido. Enseñaba yo a leer a alumnos que tenían desde cinco a diez años y a muchachotes analfabetos que me sobrepasaban en edad (Mistral, Magisterio 43).

No es casual que el magisterio haya sido la puerta de entrada de Mistral a la cultura letrada, de paso, puso en evidencia la aún relativa autonomía de la literatura. Como señala Grínor Rojo en su artículo "Mistral en la historia de la mujer latinoamericana": 
Ocurre pues que las mujeres que al abrigo de la actividad pedagógica comienzan a profesionalizarse durante esa época, en Chile, en el Cono Sur y en América Latina en general -y algo parecido se puede aducir, matizándolo, respecto de otras profesiones: enfermeras, secretarias, empleadas de tienda, funcionarias menores, todas ellas "madres" de una manera o de otra-, pueden hacerlo porque los trabajos de los que se les permite encargarse son en su mayor parte subalternos (ya que ni siquiera es muy seguro que podamos exceptuar de este aserto a las mujeres médicos cuyo desempeño profesional se circunscribió de ordinario a aquellas especialidades que ponían a salvo el pudor de su sexo) (Rojo 66).

La subalternidad, que menciona Rojo, esto es, falta de poder relativo a los centros, jugó un rol decisivo para las mujeres: entraron por una puerta lateral a la esfera pública. Mistral también se legitimó en la prensa local publicando al mismo tiempo que comienza a enseñar. Mediante este ejercicio doble, el de la pedagogía y el de la publicación, autorizó su discurso en base a la figura de la maestra militante, dispositivo retórico para legitimar su voz de niña-adulta/joven-maestra.

Desde un principio, en sus escritos la autora abogó a favor del reconocimiento de mujeres y niñas como sujetos dignos de derechos, argumentando a favor de la ley de "Instrucción Primaria Obligatoria" en Chile, para combatir el ausentismo escolar y luchar por el derecho de las niñas a educarse. Estas últimas eran dejadas en casa por "la ignorancia de los padres o sus estrecheces pecuniarias, a las que ponen remedio dando participación a las niñas de sus faenas" (Mistral, Recopilación 76). Promovió la emancipación con el acceso a la cultura letrada y la justicia en el ámbito de la educación institucional: "Si no realizamos la igualdad y la cultura dentro de la escuela, ¿dónde podrán exigirse estas cosas?" (Mistral, Magisterio 39). Su discurso se basaba en una combinación de una razón que apelaba a la justicia, junto a la moral apostólica; el magisterio ya no era un ejército militar, sino de redención. De esta forma, junto con profundizar el discurso de de Hostos, lo renovó con una retórica espiritual. Escribió textos pedagógico-políticos en los que entrelazó disciplina y religión, construyendo un modelo "religioso" de profesor/a para América. Ejemplo de estos son: "Oración de la maestra", "Oración del estudiante a la Gracia", "Palabras a los maestros", "Pensamientos pedagógicos".

Más tarde, después de 35 años de trayectoria, se consagró a nivel global ganando el Premio Nobel de Literatura en 1945. No solo fue la primera persona latinoamericana honrada con dicho galardón, sino la primera que lo 
ganó en lengua hispana (Gumucio 7). Su entrada al ámbito letrado fue difícil y traumática, teniendo que bregar con el peso de una tradición patriarcal que la rechazaba como "impropia", buscando desautorizarla y expulsarla como ajena a la norma. En efecto, su emergencia como sujeto significó una ruptura traumática de la normatividad de la esfera pública, ya que hasta casi fines del siglo XIX, la cultura letrada pública en Chile y América Latina había sido un espacio reservado exclusivamente para los varones, situación que comenzó a flexibilizarse con los mayores grados de modernización (Masiello 6; Falabella, ¿Qué será 203; Gabriela). Aquellas que rompían con este patrón patriarcal debieron pagar por su "desobediencia", haciéndose cargo de una fuerte estigmatización al ser tildadas de inadecuadas e insubordinadas. Sus personas no cumplían con los requisitos formales de pertenencia y/o propiedad (Falabella, ¿Qué será). En el caso de Mistral, su mera existencia como voz pública con autoridad significaba una amenaza para el statu quo (Rojo 59), poniendo en evidencia la flexibilización de la normatividad que excluía a las mujeres de lo público. Así, fue ejemplar cómo se la rechazó al postular a la Escuela Normal de La Serena sin siquiera rendir el examen, porque el capellán de dicha institución la consideró "un elemento perturbador por sus ideas socialistas y un tanto paganas" (Figueroa 51). Otro ejemplo paradigmático de esta "abyección" normativa fue cuando la autora abandonó Chile en 1922 para no volver, salvo por tres periodos cortos. Mistral se refería explícitamente a su imposibilidad de vivir en Chile tanto en su correspondencia, prosa como poesía (Falabella, ¿Qué será 126). Así, los manuscritos de su libro póstumo Poema de Chile señalan como uno de los objetivos de la obra "Contar finamente el que no me dejan volver" (Falabella, ¿Qué será 42).

Al no poder vivir dignamente en Chile, comenzó un largo peregrinaje por América y Europa. En 1922 parte a México para colaborar con José Vasconcelos y el Gobierno de la Revolución. En 1923 editó Lecturas para Mujeres por encargo de la Secretaría de Educación, que le encomendó "recopilar un libro de Lecturas Escolares" para las escuelas de ese país (Mistral, Lecturas XIII). "Palabras de la extranjera" antecedió dicha publicación. En este texto la autora cumplió con tranquilizar a su audiencia, señalando con un dejo amargo que la publicación no tenía una ambición nacional, sino que se limitaba a un proyecto específico, solamente para las niñas y jóvenes de la escuela que llevaba su nombre:

Mi pequeño trabajo no pretende competir con los textos nacionales, por cierto: tiene los defectos lógicos de la labor hecha por un viajero. 
He procurado compenetrarme de la sensibilidad y el pensamiento mexicanos; no he podido conseguirlo en unos cuantos meses, naturalmente. Un libro de esta índole es, a mi juicio, labor de tres años, y necesita mucha tranquilidad de espíritu y un profundo conocimiento del ambiente. Es éste el ensayo de un trabajo que realizaré algún día, en mi país, destinado a las mujeres de América. Las siento mi familia espiritual; escribo para ellas, tal vez sin preparación, pero con mucho amor (Lecturas XIII).

La falsa modestia, "Mi pequeño trabajo...", deja entrever un tono irónico que delata dolor. Este sentimiento cuaja semánticamente en torno a la palabra "viajero". Se trata de un texto donde la autora reaccionó ante el rechazo local, que estaba castigando aquello que por "ley" no tenía cabida; en este caso, su extranjería. Vemos cómo su respuesta pública ante el rechazo da cuenta de una herida latente, una hipersensibilidad. Es más, la reacción ante el rechazo se entretejió a partir de este momento sistemáticamente en su obra: es alrededor de este momento en su vida (1922-1923) en que sale por primera vez de Chile y tiene la experiencia de ser literalmente "extranjera". Comenzó a referirse a sí misma como una "eterna viajera", "exiliada" y gradual pero sistemáticamente comenzó a integrar el tópico de la extranjería y el exilio a su discurso y construcción subjetiva, proceso que culmina en Poema de Chile. En el caso del prólogo, la voz se replegó a lo que es indiscutiblemente propio, su país, su gente, su condición autodidacta y compromiso espiritual: "Es éste el ensayo de un trabajo que realizaré algún día, en mi país, destinado a las mujeres de América. Las siento mi familia espiritual; escribo para ellas, tal vez sin preparación, pero con mucho amor". Con estas palabras hacía alusión a su condición de pertenencia en el colegio que aún lleva su nombre, su condición de mujer, su condición de experta en educación y las letras, especialmente la educación de niñas y su nacionalidad y audiencia de mujeres latinoamericanas.

En este famoso prólogo, Mistral junto con autorizarse como sujeto víctima de una injusticia, se legitimó éticamente sobre la base de la responsabilidad que le cabía como mujer letrada de abrir camino para otras futuras generaciones. Por ello es que sí se sintió autorizada para aportar un libro específico para mujeres: ha "observado en varios países que un mismo Libro de Lectura se destina a hombres y mujeres en la enseñanza primaria e industrial":

Es extraño: son muy diferentes los asuntos que interesan a niños y niñas. Siempre se sacrifica en la elección de trozos la parte destinada 
a la mujer, y así, ella no encuentra en su texto los motivos que deben formar a la madre. Y sea profesionista, obrera, campesina o simple dama, su única razón de ser sobre el mundo es la maternidad, la material y la espiritual juntas, o la última en las mujeres que no tenemos hijos (Mistral, Lecturas XIII).

Con esto, Mistral se hizo cargo de una deuda moral cultural, reivindicando la maternidad como una condición que legitima a las mujeres para ejercer su derecho a participar en el espacio público con dignidad. Basándose en los dispositivos discursivos de sus antecesores, cumplió con integrar nuevos grupos, las niñas escolares, formar maestros en función de su dignidad, defendiendo su propia legitimidad como sujeto. Con esto, encarnó los proyectos letrados de los autores aquí revisados para formación y disciplinamiento de nuevos sujetos para la nación, autorizándose paradójicamente sobre la base de la maternidad de las mujeres, esto es, la cualidad ontológica que las adscribían al ámbito privado y familiar.

Sin embargo, a diferencia de lo que se observa en los textos de Bello y de de Hostos, en el discurso de Mistral se detecta un juego doble de autorización, junto con abogar por los derechos de grupos tradicionalmente excluidos de la norma y el poder, permanentemente necesitó autorizar su propia voz. Pone en evidencia la necesidad de defender su derecho a existir legítimamente en el espacio público. En efecto, en sus escritos encontramos instalados estos dos discursos: el que se refiere a una condición general de legitimación y el que se refiere a su propia autorización. A partir de ello, podemos apreciar el siempre débil escenario de legitimidad en el cual se construye el discurso de Mistral: en sus textos podemos trazar la inseguridad que causaba el no ser una voz "apropiada" a la norma, como sujeto intelectual público debió permanentemente defender su derecho a voz. Efectivamente, la entrada a la esfera pública por parte de Mistral significó una transgresión traumática de la normatividad ancestral que excluía a las mujeres de los asuntos públicos, incluyendo una alta sanción por el ejercicio visible de posiciones de poder. (Ludmer 51-52; Hurtado 163-191).

La culminación de la autorización de la voz de mujer rural es también la de la voz portadora del trauma y la abyección, ejemplificada en su libro póstumo Poema de Chile (1967), donde el almita de Mistral, una "mama", recorre el territorio de Chile de norte a sur junto a un niño indio. La "mama" educa al niño, resistiendo y subvirtiendo las categorías institucionales de la madre y de la profesora: no hay vínculo biológico, ni leche, ni cuerpo/ 
hogar/escuela. Con esta constitución de sujeto, la autora desmitificó e ironizó su propia iconización como la mítica "Maestra de América" o "Madre por excelencia" (Falabella, ¿Qué será 144). También, la "mama” conlleva marcas de clase y raza: como madre "segundona" se autoriza desde su origen rural y mestizo (tradicionalmente en las culturas americanas la mama suele ser una mujer asalariada, de una etnia autóctona o africana). Es más, la mama Gabriela es productora no de leche sino de palabras y saberes, cuyo medio de transmisión es la oralidad.

La mama fantasma le enseña a su compañero de viaje las tierras de Chile mediante el diálogo y el canto (Falabella, ¿Qué será 40-41). Viajando, los caminantes tocan, sienten, huelen y le hablan a los componentes del paisaje y es esta experiencia la que sustituye la situación tradicional de aprendizaje en el aula de la institución escolar. Un ejemplo de este tipo de diálogo es el poema "Bío-Bío":

$-¡$ No te acerques tanto, no!

Echate aquí, loco mío, y óyelo no más.

Podemos quedar con él una semana si quieres, si no me asustas así.

-¿Cómo dices que se llama?

Repite el nombre bonito.

-Bío-Bío, Bío-Bío,

qué dulce que lo llamaron

por quererle nuestros indios (Mistral, Rollo 1, 42).

El diálogo pedagógico que sostiene el almita de Mistral con el niño a lo largo del Poema de Chile se basa en la transmisión de la experiencia de vida cotidiana y rural viajera, que sobrepasa la norma letrada. Se trata de una normatividad personalizada, que se adapta de manera flexible y contextual a cada situación, que valora los nombres que fueron dados por "nuestros indios". Al respecto, Iván Carrasco explica:

Hay dos modalidades de enseñanza en Poema de Chile: una expresa, que por amor y oficio la maestra le propone al niño durante el viaje, por medio de una metodología renovada y democrática (el diálogo), propia de la Escuela Nueva y las tendencias de la pedagogía moderna; el contenido de esta enseñanza es el conocimiento y amor por su país 
como entidad global y por cada uno de sus paisajes, ambientes, seres animales, etc. Es también una enseñanza personalizada, tal como la que se busca en nuestros días, preocupada por el desarrollo del ser humano particular de acuerdo a sus potencialidades, intereses y valores (122).

Gabriela Mistral elaboró para la Escuela Nueva un discurso sobre la enseñanza vinculada a la experiencia de vida y cotidiana de una mujer popular y viajera, apegada a los saberes de la tierra, transfiriéndole el conocimiento sobre el propio país, paisaje, sus ancestros y flora y fauna, relevando también mediante el diálogo la opinión de su acompañante, junto con dignificar la subjetividad niño. Al respecto Mistral señaló:

Necesita la escuela nueva maestros que posean la gracia. La gracia significa para mí movimiento inédito del alma; cierta alegría de crear que Dios da, y que contiene su gozo de Génesis, una convicción completa de que la verdad adoptada es la mejor, ninguna concesión a los consejos del pasado abolido; ningún resquicio por donde se cuelen la muerte, el desaliento, el hombre viejo; un fervor del niño que se vea en la cara y que caliente las palabras, que se mire en el gesto y se haga palpable a las menudas acciones (Mistral, Magisterio 182).

Vemos cómo el discurso pedagógico de Mistral se construyó siguiendo el lenguaje evangélico que recuerda al de de Hostos. Al referirse a la "gracia" señaló que se trataba de una enseñanza que abogó por los principios propuestos por el autor puertorriqueño. Sin embargo, la autora acomoda estos principios al ámbito de lo espiritual y lo pequeño, de acuerdo a su propio proyecto estético, aterrizando la situación de aprendizaje a la tierra. En su discurso pedagógico se validó la informalidad de una relación que escapa a la institución escolar. En Poema de Chile culminó este proceso con la autorización de la voz autodidacta y viajera de la mama, como las abuelas ancestrales que enseñan con su conversación, representando a todas las mujeres sencillas de América e identificándose con ellas. Carrasco precisa: "su enseñanza no es un conjunto de contenidos, sino más bien un modo de caminar por la tierra propia, un modo de caminar tocando, mirando, oliendo, amando la naturaleza, las cosas, las personas humildes. Y si caminar es vivir, educar es enseñar una forma de vivir" (122). Esta forma de aprendizaje que se liga directamente con la tierra y el paisaje, el campo, lo popular y otros componentes tradicionales tiene como base la oralidad. Se trata de una propuesta autobiográfica que a la vez busca construir nación. Tal como señala Jaime Quezada: 
Poema de Chile es un oficio de creación de patria, un redescubrimiento de la entraña misma del largo país, de su naturaleza física y humana, de lo vivo y lo viviente del suelo natal; es también un testimonio de la verdadera y permanente vinculación de la autora con lo real y genuino, lo criollo y lo autóctono de la tierra chilena y su pasión por las vivencias fundamentales que la nutrieron en su infancia (118).

De esta forma, Mistral llevó a cabo una rearticulación valorativa de elementos "relegados" y "desvalorizados" del proyecto modernizador. La autora hizo uso del discurso de Bello y de de Hostos para rescatar lo que biográficamente le correspondió como lo propio: oralidad, folclore, vida privada y cotidiana de mujeres, el espacio de la infancia, la mama etc., y estos son los lugares donde se producen lenguajes "otros". La autora no solo revitalizó la norma letrada, sino que incorporó un nuevo espacio, que le era propio a la literatura. Con ello, Mistral se hizo cargo de una responsabilidad moral de reivindicar sus ancestros de mujeres educadoras tradicionalmente invisibilizadas por la normatividad patriarcal excluyente.

Si bien Bello propuso la integración de los "hermanos americanos", el proyecto emancipador de de Hostos argumentó en contra de la discriminación de la mujer, acto que instalaba en el lugar de la barbarie. Construyó de esta manera un argumento a favor del progreso, haciéndose de la ya tradicional oposición entre civilización y barbarie ${ }^{6}$. La igualdad jurídica entre ambos sexos en América fue un paso necesario para la modernización y el progreso en la "América Latina"; los que no sólo fueron sociales y políticos, sino también morales. En efecto, para de Hostos, las mujeres eran las más capaces de percibir el "cambio que se opera en el espíritu de la humanidad" (De Hostos, Ensayos 44).

Gabriela Mistral, escritora de provincia que emigró a las metrópolis nacionales y después globales, puede entenderse entonces como un fenómeno propio de los patrones de modernización. La autora logró instalarse en el espacio

$6 \quad$ El progreso en de Hostos se considera el fruto de un proceso de "rompimientos radicales" de las sociedades, una serie de desarrollos y superaciones de conflictos que conducirá hacia un devenir social más completo y humano. Se trata de un ideal utópico del progreso:

Serán un progreso, porque el día en que esos rompimientos hayan elaborado las consecuencias radicales que buscaban, la civilización fijará sus reales en el Nuevo Continente, y siendo esa civilización más completa, más humana, por ser más completa, la humanidad vivirá mejor que ha vivido, la ciencia tendrá más horizontes que descubrir, la conciencia más leyes que acatar. (de Hostos, Ensayos 50). 
letrado y utópico, legitimando su voz desde lo más íntimo y tradicionalmente excluido. En "Palabras de la extranjera" vimos cómo la diferencia discursiva de Mistral, tanto material como simbólica, funcionó basado en el trauma y como un dispositivo detonador de producciones discursivas complejas, que buscaron legitimar algo que de por sí no estaba legitimado. Sin embargo, es en Poema de Chile donde Mistral autorizó esta otra forma de educar, donde incluyó a otras familias, otras formas de ser y de educarse, ampliando el registro ético y abriendo los patrones de dignificación y acceso a la subjetividad nacional a través de la reivindicación de la mama como educadora ancestral ${ }^{7}$.

\section{BIBLIOGRAFÍA}

Bakhtin, M. M. Dialogical Imagination. Austin: Universisty of Texas Press, 1994.

Bello, Andrés. Gramática de la lengua castellana destinada al uso de los americanos. Barcelona: Linkgua ediciones, 2008.

Carrasco, Iván. "Poema de Chile: un texto pedagógico". Revista Chilena de Literatura 56 (2000): 117-125.

Cornejo Polar, Antonio. Escribir en el Aire. Lima: Editorial Horizonte, 1994.

De Hostos, Eugenio María. Obras completas. Forjando el porvenir americano. Ed. conmemorativa del gobierno de Puerto Rico (1839-1939), Volumen 12. San Juan: Editorial Cultural s.a., 1954.

Obras completas de Eugenio María Hostos: Cuento. Teatro. Poesía. Ensayo. V. I, Literatura Tomo II. Río Piedras: Universidad de Puerto Rico, 1993.

La educación científica de la mujer. Río Piedras: Editorial de la Universidad de Puerto Rico, 1993.

Ensayos. Barcelona: Linkgua ediciones, 2007.

Falabella, Soledad. ¿Qué será de Chile en el cielo? Poema de Chile de Gabriela Mistral. Santiago: LOM, 2003.

"Gabriela Mistral y Winétt de Rokha: género, discurso, sexualidad y cultura letrada pública a principios del siglo XX en Chile". Historia de las mujeres en Chile. Eds. Joaquín Fermandois Huerta y Ana María Stuven. Santiago: Taurus, en prensa.

Figueroa, Virgilio. La divina Gabriela. Santiago: Imprenta El Esfuerzo, 1933.

Gómez Asencio, José. "De "gramática para americanos" a "gramática de todos". El caso de Bello (1847)”. Revista argentina de historiografia lingüística. I/ 1 (2009), 1-18.

7 Quisiera agradecer encarecidamente la paciencia y generosidad de mi amiga Faumelisa Manquepillán con su contribución crítica sobre el valor de las educadoras ancestrales y la oralidad. $\mathrm{Su}$ aporte fue clave para terminar este trabajo. 
Gumucio Harriet, Alejandro. Gabriela Mistral y el premio Nobel. Santiago: Nascimento 1946. Halperin Donghi, Tulio. Historia contemporánea de América Latina. Buenos Aires: Aliansa, 1999. Hurtado, María de la Luz. "La performance de los Juegos Florales de 1914 y la inadecuada presencia de Gabriela Mistral en ellos”. Revista Chilena de Literatura 72. (2008): 163-191. Jaksic, Iván. Andrés Bello: la pasión por el orden. Caracas: Bid \& co. editor, 2007.

Landes, Joan B. Women and the Public Sphere in the Age of the French Revolution. Ithaca: Cornell University Press, 1988.

Ludmer, Josefina. "Las tretas del débil". La sartén por el mango. Pérez Morales, Carlos. La jeografía: Eugenio María de Hostos, maestro de geografia. San Juan: Isla Negra Editores, 2001.

Masiello, Francine. Between civilization \& barbarism. Women, nation, and literary culture in modern Argentina. Lincoln: University of Nebraska Press, 1992.

Mistral, Gabriela. Magisterio y niño. Ed. Roque Esteban Scarpa. Santiago: Ed. Andrés Bello, 1979.

Recopilación de la obra mistraliana, 1902-1922. Ed. Pedro Pablo Zegers. Santiago: Ril Editores, 2002.

Lecturas para Mujeres. México, D.F.: Porrúa, 1997.

Rollo 1 microfilm. Archivo del Escritor, Biblioteca Nacional de Chile.

Quezada, Jaime. "Poema de Chile o un oficio de creación patria". Poema de Chile de Gabriela Mistral. Barcelona: Seix Barral, 1985.

Rama, Ángel. La crítica de la cultura en América Latina. Sel. y pról. Saúl Sosnowski y Tomás Eloy Martínez. Caracas: Biblioteca Ayacucho, 1985.

La ciudad letrada. Montevideo: Arca, 1998.

Crítica literaria y utopía en América Latina. Selección y prólogo Sánchez Lozano. Medellín: Editorial Universidad de Antioquia, 2005.

Ramos, Julio. Desencuentros de la modernidad en América Latina. Santiago: Cuarto Propio, 2003.

Rojas Osorio, Carlos. Pensamiento filosófico puertorriqueño. San Juan: Isla Negra Editores, 2002. Rojo, Grínor. "Mistral en la historia de la mujer latinoamericana". En Re-leer hoy a Gabriela Mistral, mujer, historia y sociedad en América Latina. Gastón Lillo y J. Guillermo Renart (eds). Santiago: Editorial Universidad de Santiago, 1997.

Sánchez, Cecilia. Escenas del cuerpo escindido. Santiago: Editorial Cuarto Propio, 2005.

"Félix Varela, Simón Rodríguez y Andrés Bello. Reparadores del cuerpo de la lengua materna en Hispanoamérica”. Mapocho 58 (2005): 283-300.

Stuart Mill, John. "The subjection of woman" (1869). On Liberty and Other Essays. Digiread Books, 2010.

Subercaseaux, Bernardo. Historia de las ideas y de la cultura en Chile. Sociedad y cultura liberal en el siglo XIX: J.V. Lastarria. Tomo I. Santiago: Editorial Universitaria, 1997.

Torres Quintero, Rafael. "Modernidad en la "Gramática” de Don Andrés Bello". The Saurus. Boletín del Instituto Caro y Cuervo. Tomo XXI. 1 (1966) 1-16. 